\title{
Illustration
}

\section{A Case of Choroidal Metastasis from Small-Cell Lung Carcinoma}

\section{Manami Inoue, MD; Takeshi Saraya, MD, PhD; Miku Oda, MD; Masachika Fujiwara, MD, PhD; Hajime Takizawa, MD, PhD}

Department of Respiratory Medicine, Kyorin University School of Medicine, Shinkawa Mitaka City, Tokyo, Japan

\author{
"Corresponding author \\ Takeshi Saraya, MD, PhD \\ Department of Respiratory Medicine, Kyorin University School of Medicine, 6-20-2 Shinkawa Mitaka City, Tokyo I8I-86II, Japan; \\ Tel/Fax:+8I(0)-422-44-067I; E-mail: sara@yd5.so-net.ne.jp
}

\section{Article information}

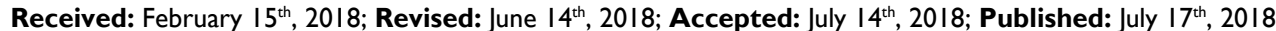

\section{Cite this article}

Inoue M, Saraya T, Oda M, Fujiwara M, Takizawa H. A case of choroidal metastasis from small-cell lung carcinoma. Cancer Stud Mol Med Open J. 20I8; 4(I): II-I2. doi: 10.17|40/CSMMOJ-4-124

\section{OVERVIEW}

A 74-year-old man visited to our hospital due to severe visual disturbance in his left eye for recent one month. Fundoscopy demonstrated the serous retinal detachment at the nose side of the left eye (Figure 1A, arrows).

At the same time, chest X-ray demonstrated a mass measuring $4 \mathrm{~cm}$ in size at the left lower lung field (Figure 2, arrow) and thoracic computed tomography (CT) depicted the mediastinal lymphadenopathies. On Hematoxylin-Eosin stain, both specimens obtained from right B10 by transbronchial lung biopsy (Figure 3A, 400X) and subcarinal lymphnodes (Figure 3B, 400X) by endobronchial ultrasound-guided transbronchial needle aspiration demonstrated abundant atypical cells with high nuclear cytoplasmic ratio. Those cells were positive for both CD56 (Figure 3C, 400X) and TTF-1 (Figure 3D, 400X), he was thus diagnosed with small cell lung carcinoma (SCLC).

For further exploring the reason for loss of visual acuity, contrast enhanced head magnetic resonance imaging (MRI) was performed. The MRI on axial, coronal, and sagittal T1 weighted images demonstrated the enhanced crescent shaped tumor (Figure 1B, 1C, 1D, arrow heads) with non-enhanced soft tissue (Figure $1 \mathrm{~B}, 1 \mathrm{D}$, arrows), which corresponded to retinal detachment and choroidal metastasis, respectively. Previous studies described that the incidence of ocular metastasis in patients with lung carcinoma ranged from $6^{1}$ to $21 \%{ }^{2}$ in post or antemortem examination. Choroid is the blood-rich tissue where the most preferable area in ocular metastasis. Physicians should be aware of the choroidal metastasis as the initial manifestation of lung carcinoma.,

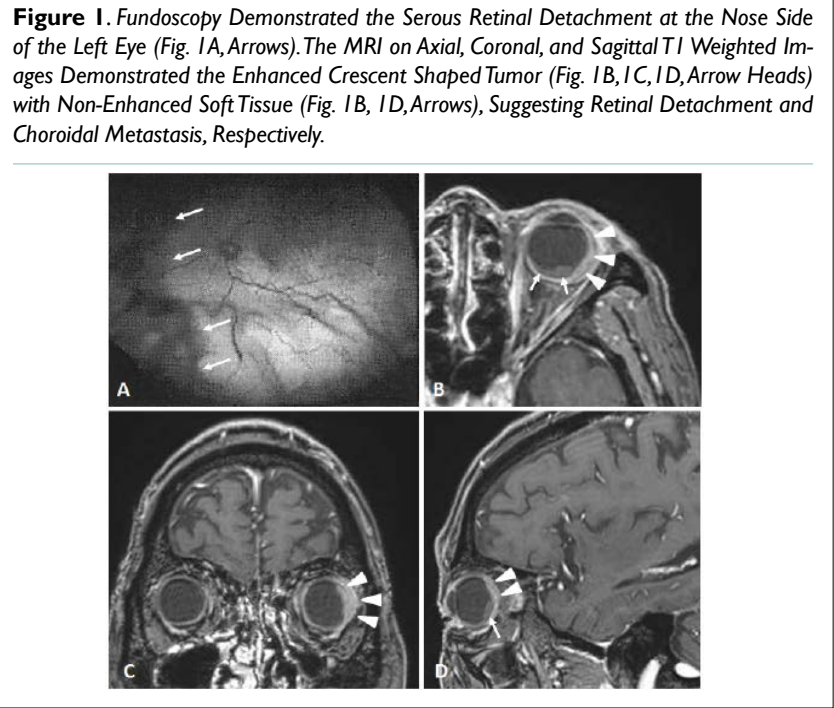

Figure 2. Chest X-Ray Demonstrated the Mass as Large as $4 \mathrm{~cm}$ at the Left Lower Lung Field (Fig. 2,Arrow).

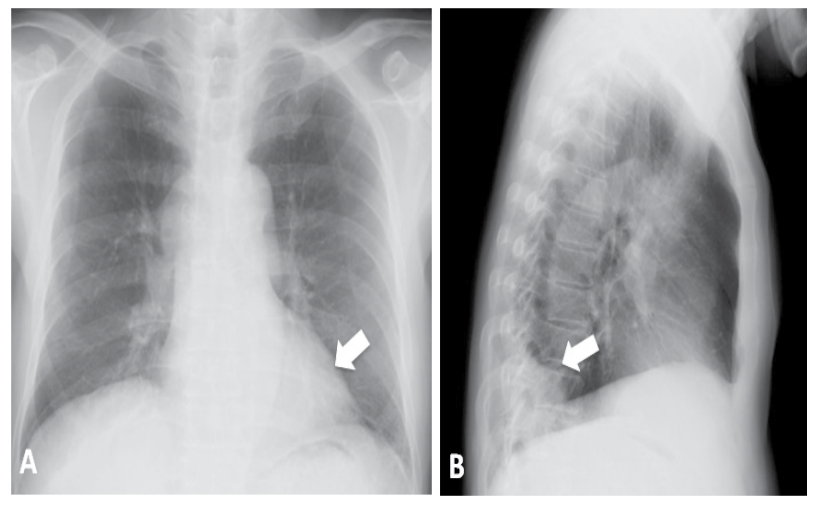

Copyright 2018 by Saraya T. This is an open-access article distributed under Creative Commons Attribution 4.0 International License (CC BY 4.0), which allows to copy, redistribute, remix, transform, and reproduce in any medium or format, even commercially, provided the original work is properly cited. 


\section{Openventio}

\section{REFERENECES}

Figure 3. On Hematoxylin-Eosin Stain, Biopsied Specimens Obtained from Right BIO (Fig. 3A, 400X) and Subcarinal Lymphnodes (Fig, 3B, 400X) Revealed Abundant Atypical Cells with High Nuclear Cytoplasmic Ratio.Those Cells were Positive for Both CD56 (Fig 3C, 400X) and TTF-I (Fig. 3D, 400X), Suggesting Small Cell Lung Carcinoma.

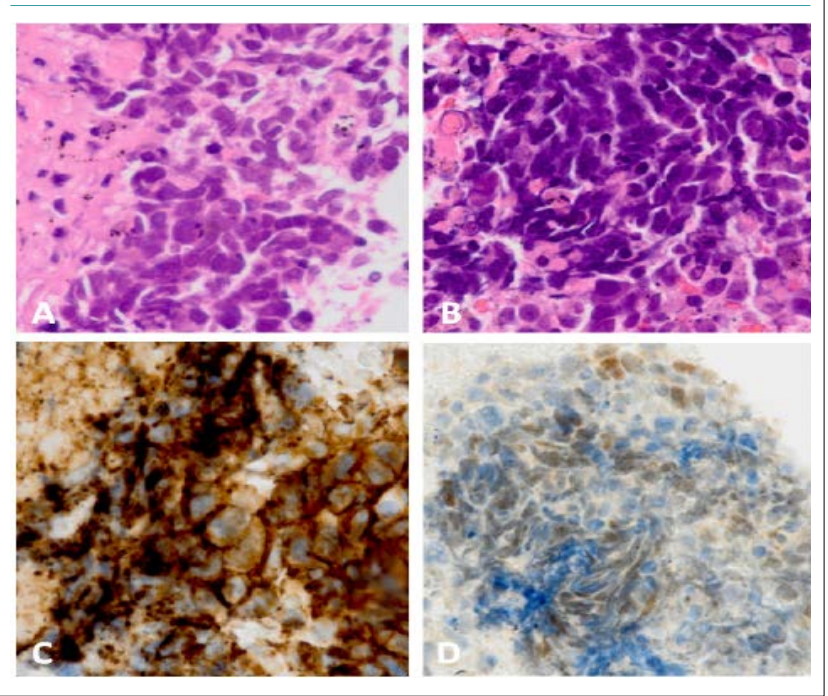

1. Bloch RS, Gartner S. The incidence of ocular metastatic carcinoma. Arch Ophthalmol. 1971; 85(6): 673-675. doi: 10.1001/archopht.1971.00990050675005

2. Shields CL, Shields JA, Gross NE, Schwartz GP, Lally SE. Survey of 520 eyes with uveal metastases. Ophthalmology. 1997; 104(8): 1265-1276. doi: 10.1016/S0161-6420(97)30148-1

3. Matsuda H, Chida K, Hashimoto D, et al. A case of adenocarcinoma of the lung presenting symptoms of choroidal metastasis as the initial clinical manifestaition. Nihon Kokyuki Gakekai Zasshi. 2004; 42(5): 410-414.

4. Ando K, Komatsu A, Matsuda M, Kaneko N. Factors affecting visual outcome in cases of lung cancer with choroidal metastasis initially presenting with ocular symptoms. JJLC. 2011; 51: 94-98. doi: https://doi.org/10.2482/haigan.51.94 